\title{
Introduction: Building the Case for Pro-Poor Adaptation
}

\section{Thomas Tanner and Tom Mitchell}

I was seldom able to see an opportunity until it had ceased to be one. (Mark Twain)

\author{
1 Understanding poverty is central to living in a \\ changing climate \\ Climate change is receiving significant levels of \\ attention across the world. The findings of the \\ world's top scientists under the Intergovernmental \\ Panel on Climate Change (IPCC) are informing calls \\ for radical limits to atmospheric greenhouse gas \\ concentrations responsible for human-induced \\ climate change (IPCC 2007). Achieving an \\ international agreement, particularly under the UN \\ Framework Convention on Climate Change \\ (UNFCCC), on emissions targets, burden sharing, \\ trading mechanisms and technological and financial \\ assistance remains a high priority concern for the \\ 'mitigation' of climate change.
}

At the same time, there is a growing acknowledgement of the need to enable human and natural systems to adjust to actual or expected climate stimuli or their effects - a process known as 'adaptation' (McCarthy et al. 2001). After playing an initially secondary role, adaptation has now become a central strand of national and international climate policy (UNFCCC 2007a). In part, this is due to improved understanding of climate change impacts and the acknowledgement of lags in the climate system; as while the amount of adaptation required will depend on our successes in mitigation, these lags commit us to some future warming over the medium term due to historic greenhouse gas emissions.

The rise of the adaptation issue can also be accredited to the increasing engagement of the development community, particularly through emphasising the differentiated nature of impacts across the world and within societies. Poorer countries and poor people living within them tend to be more seriously affected, yet have reduced assets and capacities with which to cope with and adapt to impacts (AfDB et al. 2003; Kates 2000; Stern 2007; Tanner and Mitchell, this IDS Bulletin). This has prompted a flurry of activities to integrate adaptation within development and poverty reduction programmes, often linking to communities of practice in disaster risk reduction, sustainable livelihood approaches and vulnerability assessment (Yamin et al. 2005).

These activities can usefully be viewed as a development and adaptation continuum (see Figure 1). Activities therefore range from reducing vulnerability to a broader range of shocks and stresses, through activities to improve response capacity for both climate and non-climate development processes, the incorporation of climate information to manage current and future risks, and through to actions to confront the specific challenges of climate change (McGray et al. 2007). This continuum ranges between a focus on vulnerability to a focus on impacts, from climate variability to specific climate change, with international financial flows predominantly from Official Development Assistance (ODA) on the one hand and from UNFCCC sources on the other. The spectrum also helps to frame risk, uncertainty and precaution, in which knowledge of climate change outcomes and likelihoods are characterised by ignorance, ambiguity, uncertainty and risk (Stirling 2003).

The rise of adaptation as a development issue has been influenced both by instrumental concerns around minimising threats to progress on poverty reduction (notably in the achievement of the Millennium Development Goals (MDGs)), and also by 


\section{Figure 1 The development and adaptation continuum}

\author{
Addressing the drivers \\ of vulnerability \\ Improving fundamental \\ factors to reduce \\ vulnerability to poverty \\ and harm, with limited \\ direct attention to \\ climate factors, e.g. \\ health, education, \\ women's rights, \\ accountability.
}

\section{Building response capacity}

Building robust systems for problem solving for both climate and nonclimate related activities, e.g. communications and planning processes, weather monitoring and

natural resource management practices.

\section{Climate risk management}

Integrating climate

information into

decisions to reduce negative effects on

resources and

livelihoods, e.g. disaster management, droughtresistant crops, 'climateproofing' infrastructure.

\section{Confronting climate change}

Focusing almost exclusively on climate change impacts, typically targeting climate risks that are outside historic climate variability, e.g. tackling sea level rise or glacial lake floods.

\section{Focus}

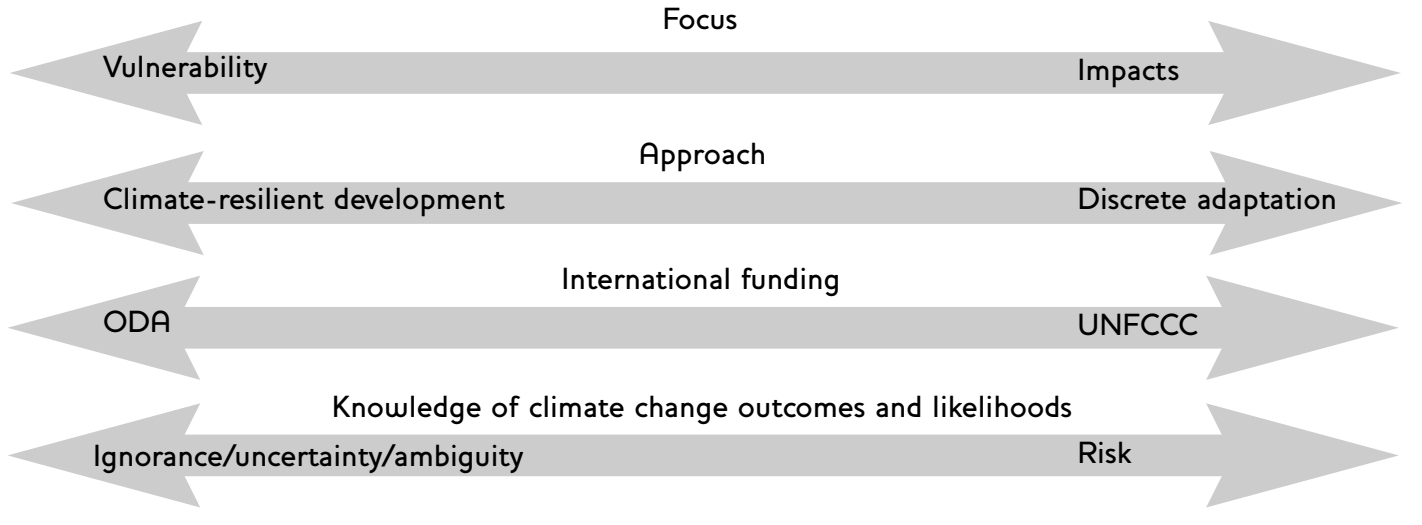

Source Adapted from McGray et al. (2007).

the injustice of impacts that are felt hardest by those who have done least to contribute to the problem, framing adaptation as an equity and rights issue (Tanner and Mitchell, this IDS Bulletin).

\section{$2 \mathrm{~A}$ pro-poor agenda for adaptation}

The central message of this IDS Bulletin is that adaptation will be ineffective and inequitable if it fails to learn from and build upon an understanding of the multidimensional and differentiated nature of poverty and vulnerability.

This collection of articles seeks to draw closer links between adaptation and poverty, and in doing so help develop an agenda for pro-poor adaptation that can inform climate-resilient poverty reduction at all scales. Such an agenda is particularly important in the context of the ongoing negotiations for a climate change agreement for the post-2012 period under the UNFCCC. It is crucial that stabilisation of greenhouse gas concentrations remains central to this agreement, both to limit the severity of climate change and to avoid shifting the burden of action onto adaptation activities among those least responsible for its causes.

Nevertheless, adaptation, and its finance, is set to play a significant role in future global agreements and the development community will necessarily need to engage with the process and the topic. Current financial flows to adaptation fall magnitudes short of the estimates that are necessary, but these are likely to increase significantly, both through aid flows and through mechanisms outside the aid architecture including the UNFCCC (Oxfam International 2007; UNDP 2007; UNFCCC 2007b; Vernon this IDS Bulletin). Ensuring that these flows are effectively, efficiently and equitably harnessed for poverty reduction is a major challenge for the development community.

\section{Tanner and Mitchell Introduction: Building the Case for Pro-Poor Adaptation}


Due to the international nature of climate change discourse, debate and action, the engagement with poverty debates has been primarily focused on the aggregate level. This has occurred internationally, such as between richer OECD nations and the G77 and China, or in the grouping of the least developed countries (LDCs) under the UNFCCC; nationally, such as highlighting the vulnerabilities of specific LDC island or low-lying deltaic states; or sub-nationally, such as in differentiating community-based adaptation approaches from top-down approaches. The result is that poverty tends to be conceptualised as linear and uni-dimensional, rather than as dynamic, multidimensional and differentiated across societies. The development community can therefore bring a wealth of existing knowledge and learning around vulnerability and poverty to ensure that adaptation processes help to leverage the greatest possible benefit for poverty reduction.

There has been important engagement in adaptation theory and practice with the concept of vulnerability and increasing attention in the field of resilience (Adger 2000, 2006; McCarthy et al. 2001; Gallopín 2006; Tompkins and Adger 2004; Yamin et al. 2005; www.steps-centre.org; www.resalliance.org). Building on this engagement, Tanner and Mitchell's subsequent article analyses adaptation in the context of chronic poverty, linking the two communities of practice. This linkage underlines the need to consider differentiated poverty in order to build suitable adaptive processes and adaptation options for different circumstances to leverage adaptation as a potential pathway out of poverty. This differentiation is further underlined by contributions from Polack, and from Demetriades and Esplen, who consider how different groups are participating in climate change adaptation at different scales. Such perspectives suggest that pro-poor adaptation can be facilitated by improving our understanding of how age, gender, ethnicity, disability and other social factors constrain or enable adaptation opportunities and can potentially contribute to the realisation of climate justice and rights to adaptation.

A pro-poor adaptation approach warrants serious attention from economists, particularly linked to the renewed focus on economic growth within poverty reduction agendas. Vernon's article sets out to establish the extent of, and gaps in, knowledge around the economics of poverty and adaptation. The article highlights the need to assess the respective roles of the private and public sectors in providing adaptation services and poverty reduction. This requires better definition of the role of government in enabling private sector engagement, thereby freeing up scarce resources to efficiently provide adaptation processes which the market fails to deliver, such as public goods like climate information or social protection mechanisms for those not served by the market.

Our ability to clarify these roles is based in part on an improved understanding of the complex processes governing the management of climate-related and other shocks and stresses to poor people's livelihoods. Prowse and Scott consider approaches centring on the mix and quantity of assets required to cope with and adapt to a changing hazard burden. Taking case studies of different approaches to adaptation, they argue that an assets-based approach highlighting the agency of poor people should be framed as central to opportunities for adaptation and poverty reduction. Sabates-Wheeler and colleagues broaden the conception of adaptation beyond climate, challenging the climate change community to improve its understanding of how livelihoods strategies can best achieve poverty reduction in ways that are most resilient in given contexts. The article demonstrates the need for shared learning with livelihoods approaches, critiquing the 'diversification as panacea' message underlining much work in the field of community-based adaptation.

\section{Delivering adaptation and poverty reduction:} governance tools and practice

Delivering adaptation processes that enhance poverty reduction relies on institutional and governance structures that have both the incentives and ability to deliver services to support the needs of different groups and sectors. Two very different articles demonstrate how climate vulnerabilities commonly stem from existing structural causes of poverty and marginalisation. Dodman and Satterthwaite use urban case studies to argue that adaptation requires improved institutional capacity and urban governance that can also meet the broader needs of the urban poor. Examining different urban actors, they highlight how much adaptation is achieved by greater effectiveness by local governments in meeting their current responsibilities for ensuring provision for infrastructure and services. Lemos and Tompkins draw on work from the disaster response community in the Cayman Islands and Brazil. Proposing a set of factors 
fundamental to reducing risk in both regions, they argue that risk reduction requires not only palliative care from disaster response but also structural reforms to address inequalities in society that cause and reproduce the root causes of vulnerability.

A growing range of tools and methods are emerging to facilitate the integration of adaptation within poverty reduction programmes (Tanner and Guenther 2007). Hedger et al.'s article in this IDS Bulletin considers the challenges for evaluating adaptation in poverty contexts across the range of adaptation activities shown in Figure 1. With rapidly expanding numbers of adaptation interventions and no clear consensus on what constitutes successful adaptation at different scales, there is an urgent need to advance thinking and techniques of evaluation. In evaluating outcomes for poor people, attention at the household level will be particularly important and can draw on established methods to assess, for example, responses to shocks and stresses and investment in assets.

A failure to serve the needs and interests of poor people provides a central critique of physical sciencefocused adaptation tools, methods and approaches. Challinor's discussion of how climate model projections can best inform adaptation that prioritises the needs of the poor is echoed in Tanner's examination of screening for development assistance portfolios and programmes. This demonstrates how decision support can enable climate-resilient development programming through a climate risk approach. Both articles call for a balance between top-down and bottom-up perspectives, with suggestions for issue-based interdisciplinarity and process-based adaptation approaches, respectively. Lessons presented in the contribution from Suarez et al. from the use of participatory video in health-risk management show

\section{Note}

1 This IDS Bulletin was stimulated by the initial discussions of this network, which develops cooperative partnerships to explore the theoretical and policy challenges related to making climate adaptation work for the poor. It also seeks to reposition the theory and discourse of climate change adaptation and in doing so how bottom-up approaches can link adaptation processes with complex poverty processes, tackling heterogeneity in vulnerable communities and enabling people to claim their rights.

The final set of articles examines some ongoing practices that warrant examination through a propoor adaptation lens. Davies et al. explore parallels between the communities of practice around disaster risk reduction, social protection and adaptation to investigate how mechanisms and instruments can deliver 'adaptive social protection'. It draws on examples in agriculture to ask how social protection can be made resilient in the face of climate change while targeting poor and vulnerable people. The article calls for social protection measures with longer timeframes that can tackle structural vulnerability to provide adaptation by transforming rather than protecting livelihoods and coping mechanisms. Hammill et al. and Pierro and Desai's contributions expand this theme by analysing microfinance and weather-based insurance schemes from a pro-poor perspective. They highlight the pitfalls of such approaches in reaching the chronically poor due to their limited asset bases and entitlements, and the importance of well-developed targeting mechanisms to optimise poverty reduction outcomes.

In the final article, Mitchell and Tanner draw together discussions from the Poverty and Adaptation Research Network, a UK-based network supported by the Economic and Social Research Council (ESRC), with articles in this IDS Bulletin to outline key areas of a research agenda to advance pro-poor adaptation policy and practice. ${ }^{1}$ This highlights key questions and issues around delivering pro-poor adaptation, claiming climate justice and rights, linking adaptation to growth agendas, and the challenges of adaptation governance across scales.

recognise the importance of science and knowledge in promoting pro-poor adaptation. Many thanks are extended to members of the network from IDS, London School of Economics, Tearfund, Christian Aid, University of Leeds, Overseas Development Institute and the Chronic Poverty Research Centre. 


\section{References}

Adger, W.N. (2006) 'Vulnerability', Global Environmental Change 16.1: 268-81

Adger, W.N. (2000) 'Social and Ecological Resilience: Are they Related?', Progress in Human Geography 24.3: 347-64

AfDB (African Development Bank); Asian

Development Bank; Department for International Development; Directorate-General for International Cooperation: the Netherlands; Directorate General for Development: European Commission; Federal Ministry for Economic Cooperation and Development: Germany; Organisation for Economic Co-operation and Development; United Nations Development Programme; United Nations Environment Programme; World Bank (2003) Poverty and Climate Change: Reducing the Vulnerability of the Poor Through Adaptation, Washington DC: World Bank, www.undp.org/ energy/povcc.htm (accessed 8 July 2008)

Gallopin, G.C. (2006) 'Linkages Between Vulnerability, Resilience, and Adaptive Capacity', Global Environmental Change 16.3: 235-316

IPCC (2007) R.K. Pachauri and A. Reisinger (eds), Climate Change 2007: Synthesis Report. Contribution of Working Groups I, II and III to the Fourth Assessment Report of the Intergovernmental Panel on Climate Change, Geneva: IPCC

Kates, R. (2000) 'Cautionary Tales: Adaptation and the Global Poor', Climatic Change 45.1: 5-17

McCarthy, J.; Canziani, O.F.; Leary, N.A.; Dokken, D.J. and White, K.S. (eds) (2001) Climate Change 2001: Impacts, Adaptation and Vulnerability, Cambridge: Cambridge University Press

McGray, H.; Hammill, A. and Bradley, R. (2007) Weathering the Storm: Options for Framing Adaptation and Development, Washington DC: World Resources Institute, http://pdf.wri.org/ weathering_the_storm.pdf (accessed 14 July 2008)
Oxfam International (2007) Adapting to Climate Change: What's Needed in Poor Countries, and Who Should Pay, Oxfam Briefing Paper 104, Oxford: Oxfam International Secretariat

Stern, N. (2007) The Economics of Climate Change: The Stern Review, Cambridge: Cambridge University Press

Stirling, A. (2003) 'Risk, Uncertainty and Precaution: Some Instrumental Implications from the Social Sciences', in F. Berkhout, M. Leach and I. Scoones (eds), Negotiating Environmental Change: New Perspectives from Social Science, London: Edward Elgar

Tanner, T.M. and Guenther, B. (2007) Sharing Climate Adaptation Tools: Improving Decision-making for Development, Report of Geneva Workshop, 11-12 April, IDS, IISD and World Bank

Tompkins, E.L. and Adger, W.N. (2004) 'Does Adaptive Management of Natural Resources Enhance Resilience to Climate Change?', Ecology and Society 9.2: 10

UNDP (2007) Human Development Report 2007/2008 Fighting Climate Change: Human Solidarity in a Divided World, New York: United Nations Development Programme

UNFCCC (2007a) Bali Action Plan, Decision 1/CP.13. Document FCCC/CP/2007/6/Add.1. Bonn: United Nations Framework Convention on Climate Change

UNFCCC (2007b) Report on Existing and Potential Investment and Financial Flows Relevant to the Development of an Effective and Appropriate International Response to Climate Change, Bonn: UNFCCC Secretariat

Yamin, F.; Rahman, A. and Huq, S. (2005)

'Vulnerability, Adaptation and Climate Disasters: $A$ Conceptual Overview', IDS Bulletin 36.4: 1-14 